\title{
Formulation development and evaluation of Glibenclamide loaded Eudragit RLPO microparticles
}

\author{
*Balagani Pavan Kumar'1, Irisappan Sarath Chandiran², Korlakunta Narasimha Jayaveera ${ }^{3}$ \\ ${ }^{1}$ Asst. Professor, Department of Pharmaceutics, Gokula Krishna College of Pharmacy, Sullurpet-524121, A.P, India \\ ${ }^{2}$ Prof E Principal, Department of Pharmaceutics, Gokula Krishna College of Pharmacy, Sullurpet-524121, A.P, India \\ ${ }^{3}$ Director, International Science-Tech Research Institute, Anantapur - 515 001, A.P, India
}

\begin{abstract}
The objective of the present investigation was to formulate and evaluate microencapsulated Glibenclamide produced by the emulsion - solvent evaporation method. Microparticles were prepared using Eudragit RLPO by emulsion solvent evaporation method and characterized for their micromeritic properties, encapsulation efficiency, particle size, drug loading, FTIR, DSC, SEM analysis. In vitro release studies were performed in phosphate buffer ( $\mathrm{pH}$ 7.4). Stability studies were conducted as per ICH guidelines. The resulting microparticles obtained by solvent evaporation method were free flowing in nature. The mean particle size of microparticles ranges from $134.49-179.72 \mu \mathrm{m}$ and encapsulation efficiency ranges from $92.30-98.32 \%$. The infrared spectra and differential scanning calorimetry thermographs confirmed the stable character of Glibenclamide in the drug-loaded microparticles. Scanning electron microscopy revealed that the microparticles were spherical in nature. In vitro release studies revealed that the drug release was sustained up to $12 \mathrm{hrs}$. The release kinetics of Glibenclamide from optimized formulation followed zero-order and peppas mechanism. The mechanism of drug release from the microparticles was found to be non-Fickian type. Eudragit RLPO microparticles containing Glibenclamide could be prepared successfully by using an emulsion solvent evaporation technique, wh ich will not only sustain the release of drug but also manage complicacy of the diabetes in a better manner.
\end{abstract}

Key Words: Microencapsulation, controlled release, diabetes mellitus, sulphonyl ureas, in vitro evaluation, release kinetics.

\section{INTRODUCTION}

Glibenclamide (Tripathi 2008, Coppack et al., 1990, Langer et al., 2007) is an oral Antidiabetic agent which is widely used in the management of non-insulin dependent diabetes mellitus (type II). It is a second generation sulphonyl urea which is more potent than the first generation drugs in this class. Its biological half-life is 4$6 \mathrm{hrs}$. Due to its low biological half-life (5 hrs), it requires frequent administration to maintain plasma concentration. This causes inconvenience to the patient and also leads fluctuations in plasma drug concentration that may cause inferior therapeutic effects or toxic effects. Therefore, development of controlled release dosage forms would clearly be beneficial in terms of decreased dosage requirements, thus increase patient compliance.

Microencapsulation is a well-known method for the preparation of microparticles for controlled release. Among the various methods developed for formulation of microparticles, solvent evaporation method is one of the mostly widely used one to formulate microparticles because of its ease of fabrication without compromising the activity of drug (Behera et al., 2008). In the present investigation Eudragit RLPO is used as a rate retardant polymer. Eudragit RLPO is a water insoluble polymer which is widely used as a wall material for controlled release microparticles. This is due to its biocompatibility, good stability, easy fabrication and low cost (Sahoo et al., 2005). In the present investigation solvent evaporation method is employed with an objective of developing microparticles for oral controlled release and subjected for

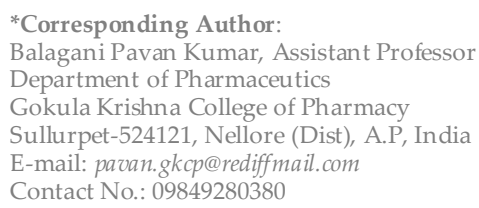

evaluation in terms of drug content, encapsulation efficiency, size analysis, compatibility studies and in-vitro release studies.

\section{MATERIALS AND METHODS}

\section{Materials}

Glibenclamide was obtained as gift sample from Orchid Pharma Ltd, Chennai. Eudragit RLPO (Natco Pharma; Hyderabad, India), Acetone, liquid paraffin, tween 80, span 80 (Loba chemie Pvt. Ltd. Mumbai, India) and the chemical reagents used were of analytical grade.

\section{Preparation of Microparticles}

The microparticles were prepared by emulsion solvent evaporation technique (Chowdary et al., 2003). Glibenclamide microparticles were formulated by varying the drug and polymer ratios and by varying the surfactants (table 1). Weighed amount of drug and polymer were dissolved in $10 \mathrm{ml}$ of acetone. The organic solution was then slowly added to $100 \mathrm{ml}$ of liquid paraffin containing $1 \%$ surfactant with constant stirring for $1 \mathrm{~h}$. The resulting microparticles were separated by filtration and washed with petroleum ether. The microparticles finally air dried over a period of $12 \mathrm{hrs}$ and stored in a dessicator.

\section{Characterization of Microparticles \\ Yield of Microparticles (Hazedar et al., 2004)}

Microparticles recovered at the end of preparation were weighed and the yield was calculated as a percentage of the total amounts of polymer and drug added during the preparation of microparticles.

\section{Flow properties (Trivedi et al., 2008)}

Angle of repose

Angle of repose is defined as the maximum angle possible between the surface of the pile of the powder and the 
Table 1: Composition of Glibenclamide microparticles.

\begin{tabular}{ccccccccc}
\hline Ingredients & \multicolumn{8}{c}{ Formulations } \\
\cline { 2 - 10 } & F 1 & F 2 & F 3 & F 4 & F 5 & F 6 & F 7 & F 8 \\
\hline Glibenclamide (gm) & 1 & 1 & 1 & 1 & 1 & 1 & 1 & 1 \\
Eudragit RLPO (gm) & 1 & 1.5 & 2 & 3 & 1 & 1.5 & 2 & 3 \\
Acetone (ml) & 10 & 10 & 10 & 10 & 10 & 10 & 10 & 10 \\
Span 80 \% & 1 & 1 & 1 & 1 & - & - & - & - \\
Tween 80 \% & - & - & - & - & 1 & 1 & 1 & 1 \\
Liquid Paraffin(ml) & 100 & 100 & 100 & 100 & 100 & 100 & 100 & 100 \\
\hline
\end{tabular}

horizontal plane. The flow characteristics of different microparticles were studied by measuring the angle of repose employing fixed funnel method. The angle of repose was calculated by using the following formula:

$\operatorname{Tan} \theta=\frac{\text { Height of the pile }}{\text { radius of the base of the pile }}$

where $\theta=\tan ^{-1}(h / r), \theta=$ angle of repose.

Bulk density \& tapped density

Bulk density and tapped density were measured by using $10 \mathrm{ml}$ of graduated cylinder. The pre weighed sample was placed in a cylinder; its initial volume was recorded (bulk volume) and subjected to tapings for 100 times. Then the final volume (tapped volume) was noted down. Bulk density and tapped density were calculated from the following formula:

Bulk density $=\frac{\text { Mass of microparticles }}{\text { Bulk volume }}$
Tapped density $=\frac{\text { Mass of microparticles }}{\text { Tapped volume }}$

\section{Carr's Index}

Compressibility index (CI) or Carr's index value of microparticles was computed according to the following equation:

Carr's Index $(\%)=\frac{\text { Tappeddensity }- \text { Bulk density }}{\text { Tappeddensity }}$ X100

\section{Hausner's Ratio}

Hausner ratio of microspheres was determined by comparing the tapped density to the bulk density using the equation:

$$
\text { Hausner's Ratio }=\frac{\text { Tappeddensity }}{\text { Bulk density }}
$$

\section{Size distribution and size analysis}

For size distribution analysis, $250 \mathrm{mg}$ of the microparticles of different sizes in a batch were separated by sieving, using a range of standard sieves. The amounts retained on different sieves were weighed. The mean particle size of the microparticles was calculated by the formula (Gohel et al., 1998).

Mean Particle Size $=\frac{\left.\sum \text { (Mean particle size of the fraction } \times \text { Weight fraction }\right)}{\sum(\text { Weight fraction })}$ $\sum$ (Weight fraction)

\section{Estimation of drug content}

An accurately weighed portion of microparticles equivalent to $5 \mathrm{mg}$ of Glibenclamide were weighed and transferred in to a mortar. Powdered and dissolved in 100 $\mathrm{ml}$ of $\mathrm{pH} 7.4$ phosphate buffer, suitably diluted the absorbance of the resulting solution was measured at 228 nm (Kumar et al., 2001).

\section{Entrapment efficiency}

Entrapment efficiency was calculated using the formula (Lin et al., 1999):

Entrapment efficiency $=\frac{\text { Estimated percent drug content }}{\text { Theoretical percent drug content }} \times 100$

Estimated percent drug content was determined from the analysis of microparticles and the theoretical percent drug content was calculated from the employed core: coat ratio in the formulation of microparticles.

\section{Morphological characterization by SEM}

Morphology and surface characteristics were studied by Scanning Electron Microscopy. The samples for the SEM analysis were prepared by sprinkling the microparticles on one side of the double adhesive stub. The stub was then coated with fine gold dust. The microparticles were then observed with the scanning electron microscope (Leica Electron Optics, Cambridge, USA) at $10 \mathrm{kv}$.

Fourier Transform Infrared Spectroscopy (FTIR) studies The pure drug and optimized formulations were subjected for FTIR analysis. The samples were scanned over a range of $4000-400 \mathrm{~cm}^{-1}$ using Fourier transformer infrared spectrophotometer. Spectrums were analyzed for drug polymer interactions.

\section{Differential Scanning Calorimetry (DSC) studies}

The pure drug and optimized formulation were subjected to differential scanning calorimeter equipped with an intra-cooler (NETZSCH, Japan.). Indium/zinc standards were used to calibrate the DSC temperature and enthalpy scale. The sample were sealed in aluminum pans and heated at a constant rate $20^{\circ} \mathrm{C} / \mathrm{min}$ over a temperature range of $20-250^{\circ} \mathrm{C}$. An inert atmosphere was maintained by purging nitrogen gas at a flow rate of $50 \mathrm{ml} / \mathrm{min}$.

\section{Drug release studies}

Release of Glibenclamide from the microparticles, was studied in phosphate buffer of pH $7.4(900 \mathrm{ml})$ using Eight Station Dissolution Rate Test Apparatus (M/s. Electrolab) with a paddle stirrer at $100 \mathrm{rpm}$ and at $37 \pm 0.5^{\circ} \mathrm{C}$. A sample of microparticles equivalent to $5 \mathrm{mg}$ of Glibenclamide was used in each test. Samples were withdrawn through a filter (0.45) at different time intervals and were assayed at $228 \mathrm{~nm}$ for Glibenclamide using Shimadzu double beam UV spectrophotometer. The drug release experiments were conducted in triplicate (Chalk et al., 1986).

\section{Dissolution kinetics}

The rate and the mechanism of release of Glibenclamide from the prepared microparticles were analyzed by fitting the dissolution data into (Salomon et al., 2002) following equations:

(1) Zero-order equation

$\mathrm{Q}=\mathrm{Q} \circ-k \circ t$, where $\mathrm{Q}$ is the amount of drug released at time $t$, and $k_{0}$ is the release rate.

(2) First order equation

$\ln \mathrm{Q}=\ln \mathrm{Q} \circ-\mathrm{k}_{1} \mathrm{t}$, where $\mathrm{k}_{1}$ is the release rate constant

(3) Higuchi's equation

$\mathbf{Q}=\mathbf{k}_{2} \mathbf{t}_{1 / 2}$, where $\mathrm{Q}$ is the amount of the drug released at time $t$ and $k_{2}$ is the diffusion rate constant. 
Table 2: Micromeritic properties of Glibenclamide microparticles.

\begin{tabular}{ccccccc}
\hline Formulation code & $\begin{array}{c}\text { Angle of repose } \\
\text { (q) }\end{array}$ & $\begin{array}{c}\text { Bulk Density } \\
\text { (g/cm3) }\end{array}$ & $\begin{array}{c}\text { Tapped Density } \\
\text { (g/cm3) }\end{array}$ & $\begin{array}{c}\text { Carr's } \\
\text { Index }\end{array}$ & $\begin{array}{c}\text { Hausner's } \\
\text { Ratio }\end{array}$ & $\begin{array}{c}\text { Average Particle } \\
\text { Size }(\boldsymbol{\mu m})\end{array}$ \\
\hline F 1 & 27.14 & 0.508 & 0.591 & 13.98 & 1.162 & 134.49 \\
F 2 & 25.21 & 0.519 & 0.606 & 13.64 & 1.157 & 148.12 \\
F 3 & 23.88 & 0.523 & 0.604 & 13.41 & 1.154 & 158.81 \\
F 4 & 22.12 & 0.531 & 0.608 & 12.66 & 1.22 & 173.42 \\
F 5 & 27.53 & 0.749 & 0.884 & 15.28 & 1.18 & 159.86 \\
F 6 & 25.16 & 0.767 & 0.898 & 14.58 & 1.16 & 170.82 \\
F 7 & 23.31 & 0.781 & 0.903 & 13.49 & 1.14 & 179.72 \\
F8 & 21.14 & 0.822 & 0.943 & 12.86 & 1.14 & \\
\hline
\end{tabular}

Table 3: Percentage yield, \% drug content and \% encapsulation efficiency of Glibenclamide microparticles.

\begin{tabular}{cccc}
\hline $\begin{array}{c}\text { Formulation } \\
\text { code }\end{array}$ & \% Yield & $\begin{array}{c}\text { \% Drug } \\
\text { Content }\end{array}$ & $\begin{array}{c}\text { \% Encapsulation } \\
\text { Efficiency }\end{array}$ \\
\hline F 1 & 82.5 & 47.12 & 94.24 \\
F 2 & 91.6 & 38.15 & 95.37 \\
F 3 & 93.33 & 32.31 & 96.93 \\
F 4 & 93.25 & 24.36 & 97.44 \\
F 5 & 93.5 & 46.15 & 92.30 \\
F 6 & 96.4 & 37.87 & 94.67 \\
F 7 & 95.67 & 32.42 & 97.26 \\
F8 & 98.25 & 24.58 & 98.32 \\
\hline
\end{tabular}

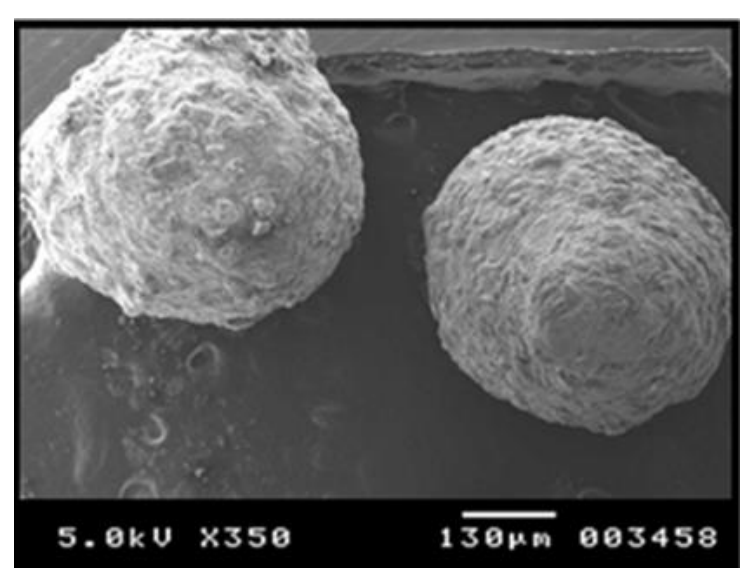

Figure 1: SEM Photograph of Glibenclamide microparticles.

Table 4: Release kinetics of Glibenclamide microparticles.

\begin{tabular}{|c|c|c|c|c|c|c|c|c|c|}
\hline \multirow{2}{*}{$\begin{array}{c}\text { Formulation } \\
\text { Code }\end{array}$} & \multicolumn{4}{|c|}{ Correlation Coefficient Values $\left(\mathbf{R}^{2}\right)$} & \multirow{2}{*}{$\begin{array}{c}\text { Release Rate } \\
\text { Constant } \\
(\mathrm{mg} / \mathrm{hr}) \mathrm{Ko}\end{array}$} & \multirow[t]{2}{*}{$\mathbf{t}_{50 \%}$} & \multirow[t]{2}{*}{$t_{90 \%}$} & \multirow{2}{*}{$\begin{array}{l}\text { Wall Thickness } \\
\qquad(\mu \mathrm{m})\end{array}$} & \multirow{2}{*}{$\begin{array}{c}\mathrm{n} \\
\text { value }\end{array}$} \\
\hline & Zero Order & $\begin{array}{l}\text { First } \\
\text { Order }\end{array}$ & $\begin{array}{c}\text { Higuchi } \\
\text { Model }\end{array}$ & $\begin{array}{l}\text { Peppas } \\
\text { Model }\end{array}$ & & & & & \\
\hline F 1 & 0.9963 & 0.8175 & 0.9457 & 0.9972 & 0.62 & 4.03 & 7.25 & 27.39 & 0.8162 \\
\hline F 2 & 0.9928 & 0.8020 & 0.9236 & 0.9997 & 0.57 & 4.3 & 7.1 & 35.27 & 0.9650 \\
\hline F 3 & 0.9993 & 0.7977 & 0.9136 & 0.9999 & 0.55 & 4.5 & 8.2 & 45.46 & 1.0618 \\
\hline F 4 & 0.9991 & 0.7984 & 0.9147 & 0.9993 & 0.49 & 5.1 & 9.2 & 50.24 & 1.0840 \\
\hline F 5 & 0.9702 & 0.8290 & 0.9741 & 0.9971 & 0.74 & 3.3 & 6.0 & 26.11 & 0.6162 \\
\hline F 6 & 0.9939 & 0.8168 & 0.9496 & 0.9946 & 0.67 & 3.7 & 6.6 & 34.13 & 0.7970 \\
\hline F 7 & 0.9971 & 0.8138 & 0.9427 & 0.9947 & 0.62 & 4.0 & 7.2 & 44.16 & 0.8301 \\
\hline F8 & 0.9994 & 0.8085 & 0.9271 & 0.9971 & 0.52 & 4.8 & 8.6 & 49.14 & 0.9290 \\
\hline
\end{tabular}

The dissolution data was further analyzed to define the mechanism of release by applying the dissolution data following the empirical equation:

(4) $\mathrm{Q}=\frac{\mathrm{M}_{\mathrm{t}}}{\mathrm{M} \alpha} \times K t n$, where $\mathrm{Mt} / \mathrm{M}_{\alpha}$ is the fraction of drug released at time t. $\mathrm{K}$ is a constant and $\mathrm{n}$ characterizes the mechanism of drug release from the formulations during dissolution process.

\section{Stability study}

The formulation was subjected to accelerated stability studies as per ICH (The International Conference of Harmonization) guidelines. The optimized formulation was sealed in an aluminum foil and stored at $25 \pm 2{ }^{\circ} \mathrm{C}, 60$ $\pm 5 \% \mathrm{RH}$ and at $40 \pm 2{ }^{\circ} \mathrm{C}, 75 \pm 5 \% \mathrm{RH}$ for 3 months (Dashora et al., 2007). Microparticles were periodically removed and evaluated for physical characteristics and in-vitro drug release.

\section{RESULTS AND DISCUSSION}

Glibenclamide loaded Eudragit RLPO microparticles were successfully formulated by emulsion solvent evaporation method. In these formulations, span 80 and tween 80 are used as surfactants and the optimum concentration of each is $1 \% \mathrm{w} / \mathrm{v}$. A total number of eight batches were formulated by varying the process variables like change in polymer concentration and type of surfactant. The detailed composition of microparticles is shown in table 1. These microparticles were evaluated for their percentage yield, flow properties, size analysis, percent drug content, percent encapsulation efficiency and morphological characterization, FTIR studies, DSC analysis, in vitro release studies and stability studies.

The angle of repose values of all the formulations were found to be in the range of $21.14-27.53$, i.e. less than 30 , which shows the free flowing nature of the prepared microparticles. Bulk density and tapped density showed good packability of the microparticles. Carr's index ranges from $12.66 \%$ to $15.28 \%$, indicating excellent compressibil- 

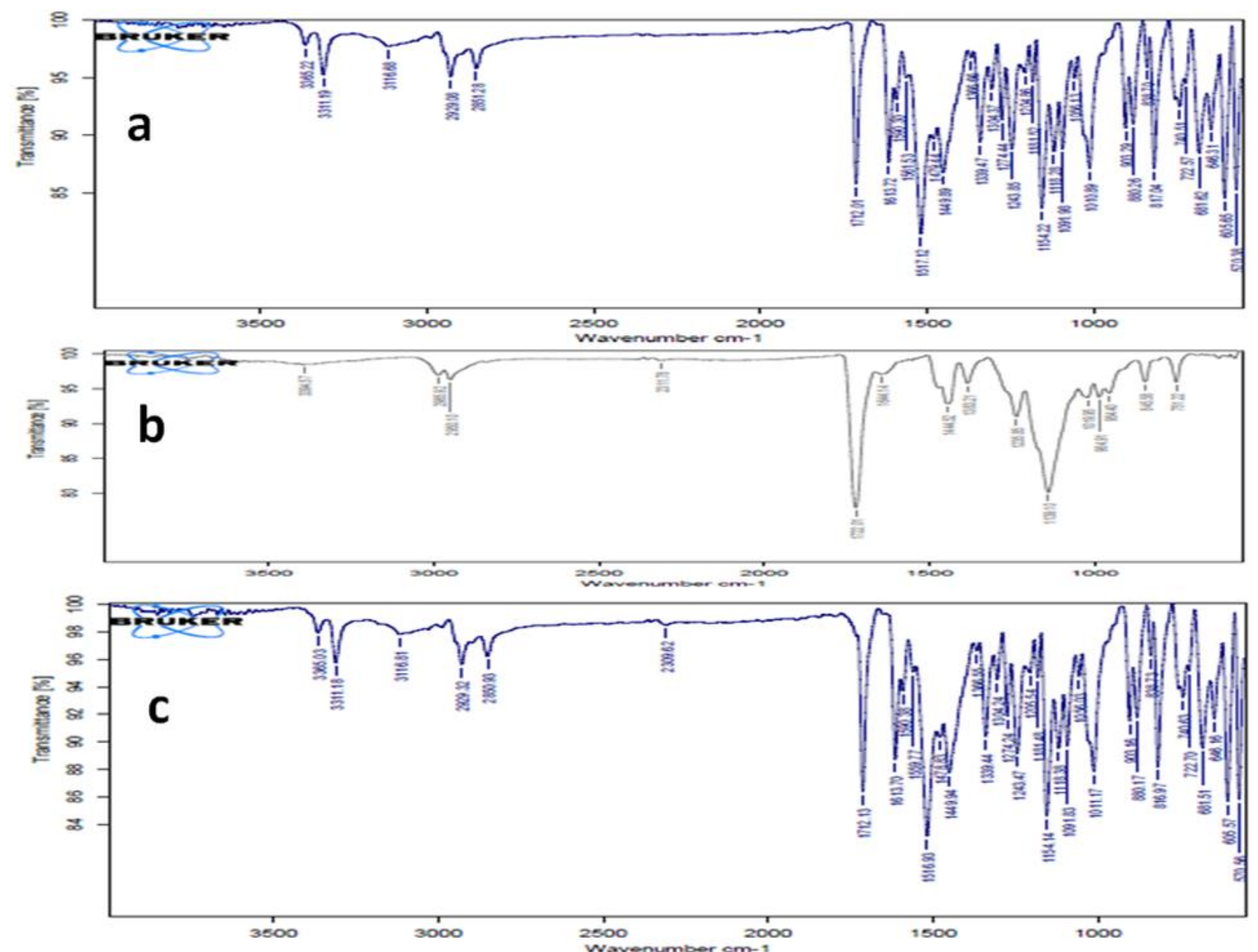

Figure 2: FTIR Spectrums of (a) Glibenclamide, (b) Eudragit RLPO, (c) Glibenclamide microparticles.

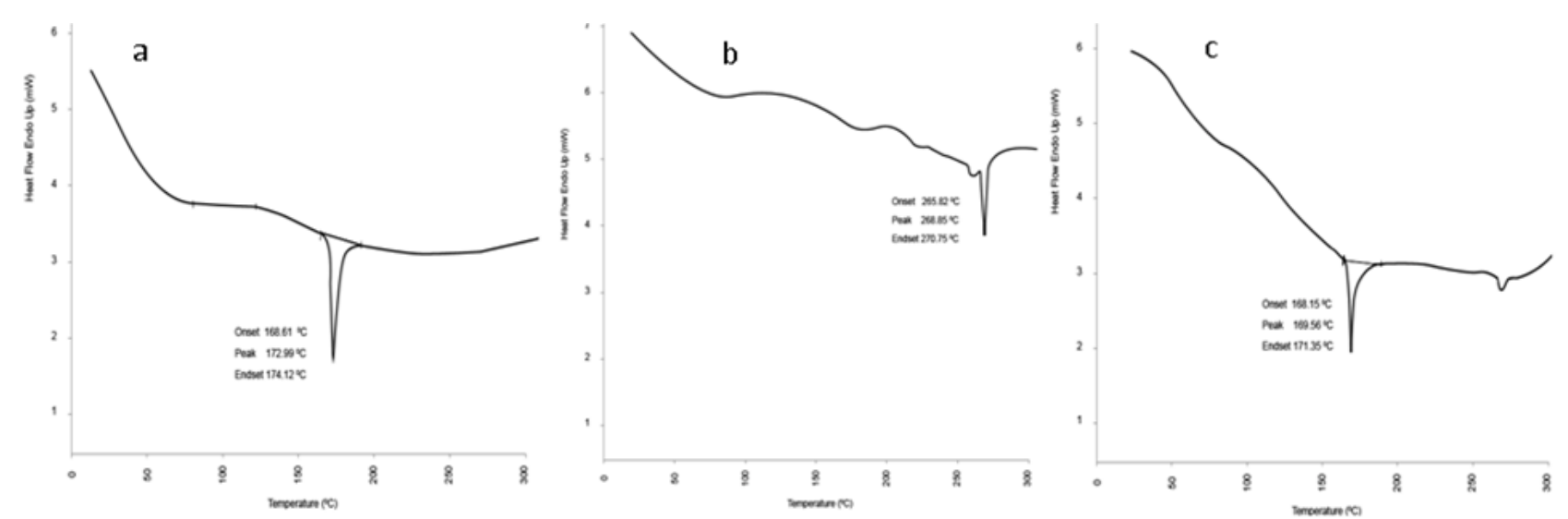

Figure 3: DSC thermograms of (a) Glibenclamide, (b) Eudragit RLPO, (c) Glibenclamide microparticles. 

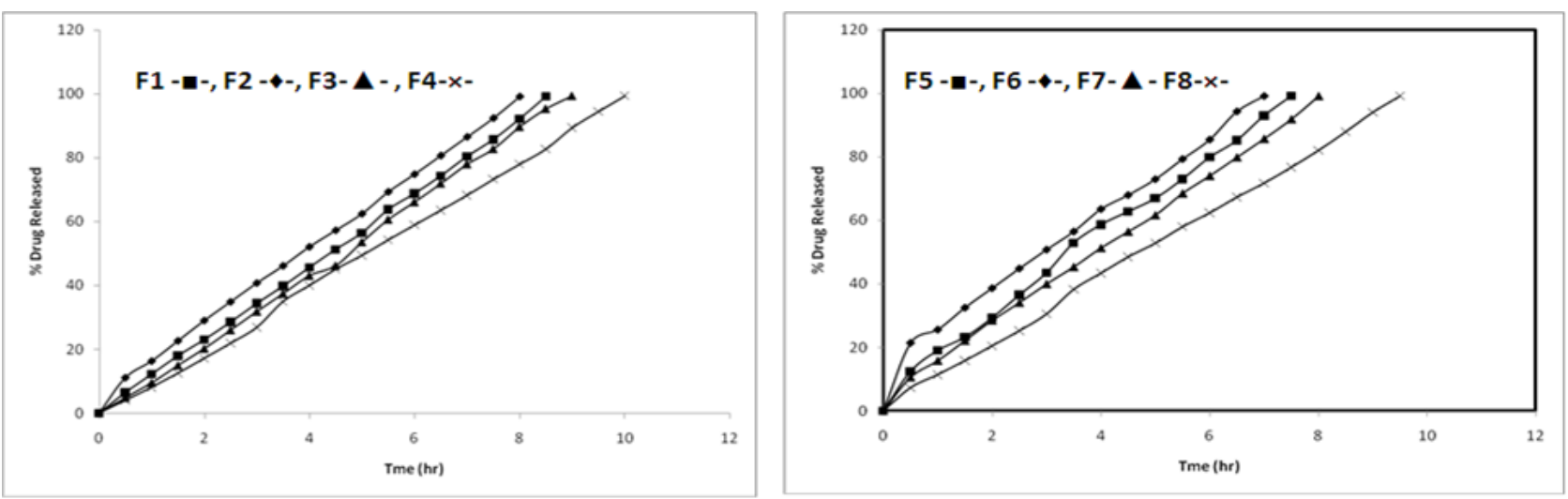

Figure 4: Release profiles of Glibenclamide microparticles.
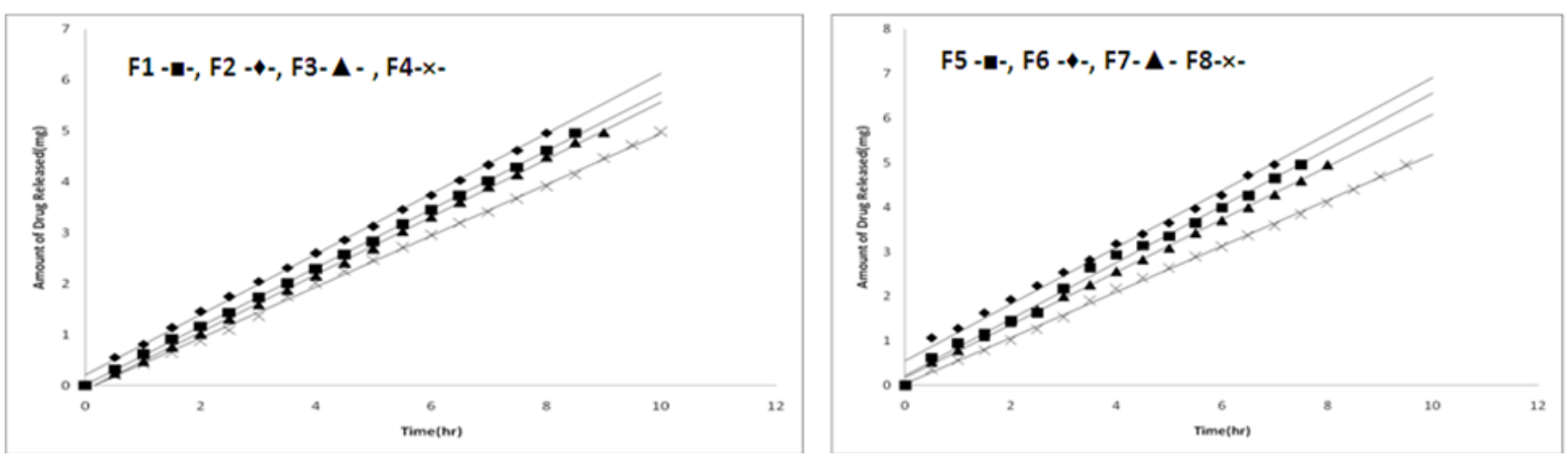

Figure 5: Zero order plots of Glibenclamide microparticles.
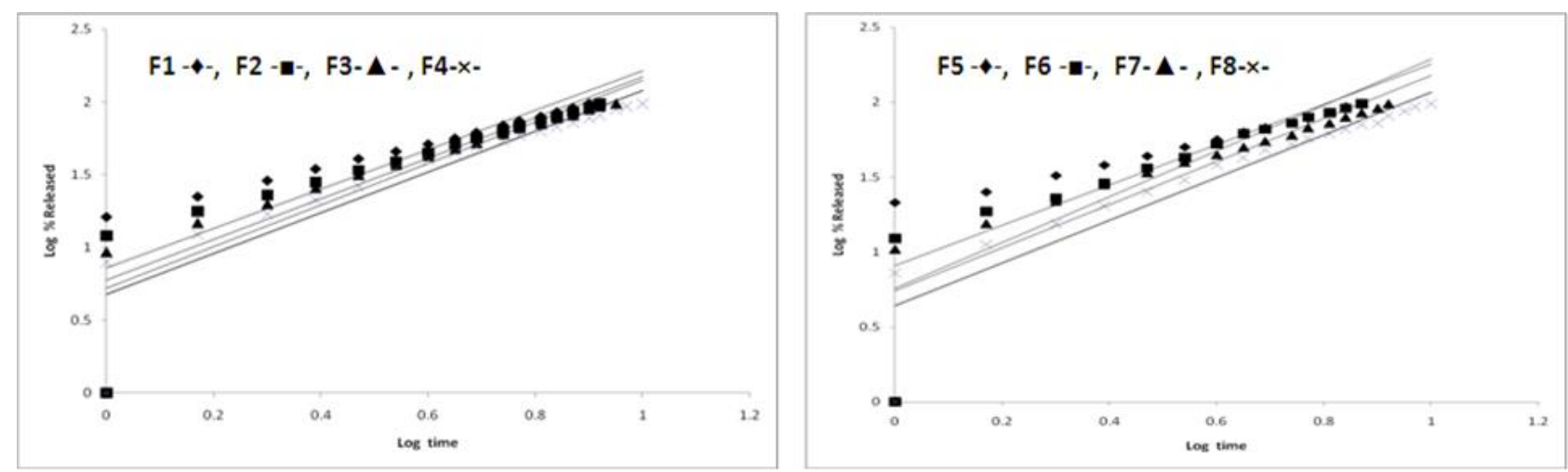

Figure 6: Peppas plots of Glibenclamide microparticles.
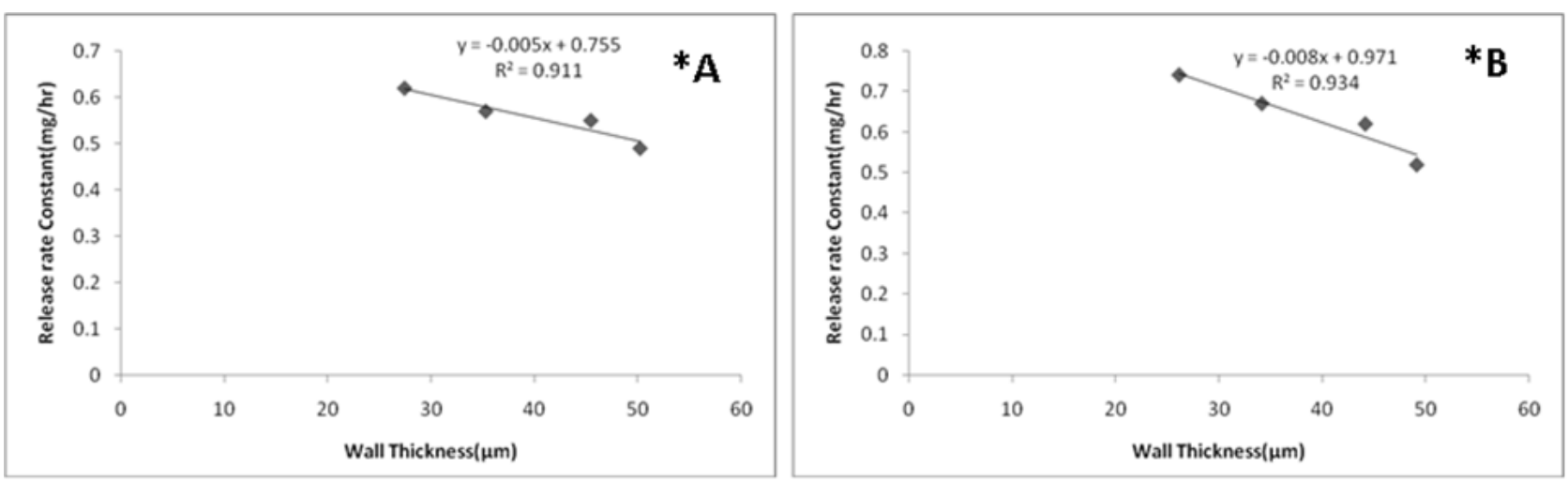

Figure 7: Correlationship between wall thickness and release rate constant of Glibenclamide microparticles prepared with Eudragit RLPO ( ${ }^{*} \mathrm{~A}$-Tween 80 as surfactant and ${ }^{*} \mathrm{~B}$-Span 80 as surfactant). 
ity. Hausner's ratio ranges from 1.14 to 1.22 , i.e. all the formulations showed that they had satisfactory flow properties. Upon considering the micromeritic properties of all the formulations, F8 had the best flow property. The results are depicted in table 2 .

The particle size analysis reveals that, with the considerable increase in the concentration of Eudragit RLPO, the mean particle size of microparticles also increased. The results are shown in table 2.

It was identified that, as the polymer ratio and the product yield directly proportional to each other. The percent yield varies from 82.5 to $98.25 \%$. The percent drug content in the microparticles was found to be 24.36 to 47.12. The percent drug content decreases with increase in polymer concentration. The percent of encapsulation efficiency ranges from 92.30 to 98.32 . The encapsulation efficiency increases with the increase in polymer concentration. The yield of microparticles, percent drug content and encapsulation efficiency data are shown in table 3.

The SEM studies clearly showed that the obtained microparticles exhibit good spherical nature. Scanning electron microscopic photographs of microparticles are shown in figure 1.

Glibenclamide shows prominent peaks at wave numbers were 3311.19, (N-H), $2929.06(\mathrm{C}-\mathrm{H}), 2851.28(\mathrm{O}-\mathrm{H}), 1449.29$ and $1517.12(\mathrm{~N}=\mathrm{O}), 1154.22(\mathrm{C}-\mathrm{N})$ and $1010.89(\mathrm{C}-\mathrm{O})$. The spectra of optimized microparticles exhibited all the principle peaks present in the Glibenclamide pure drug which indicates the stable nature of the drug during encapsulation. The FTIR Spectra's are shown in figure 2.

The Glibenclamide thermal curve shows a sharp peak at $172.99^{\circ} \mathrm{C}$ which corresponds to its melting point. The pure polymer Eudragit RLPO exhibits a peak at $268.85^{\circ} \mathrm{C}$. The peak of Glibenclamide was observed in the thermogram of prepared microparticles, thus the results revealed that there were no major interactions between the drug and the polymer during microencapsulation process. The DSC thermograms were shown in figure 3.

The Glibenclamide microparticles were subjected to in-vitro release studies by employing $7.4 \mathrm{pH}$ phosphate buffer and the drug release profiles were shown in figure 4. When the amount of drug release values are plotted against time straight lines were obtained in all the cases indicating that the rate of drug release from these microparticles followed zero order kinetics and the graphs are shown in figure 5. To ascertain the mechanism of drug release from various microparticles plot of log \% released vs. log time (Peppas plots) were drawn. The plots were found to be linear with all formulations. The peppas plots are shown in figure 6 .

Release Kinetic studies of Glibenclamide microparticles were shown in table 4 . The exponential coefficient (n) values were found to be in between 0.6162 to 1.0840 indicating non-fickian mechanism. These results indicated that the release rate was found to decrease with increase in concentration of coating material applied. The wall thickness of microparticles was found to be increased with the increase in concentration of coating material applied. A good correlationship sustained in between wall thickness and release rate constant and the graphs were shown in figure 7.

The stability studies were carried out for the prepared microparticles. After 3 months storage of formulations at $30 \pm 2{ }^{\circ} \mathrm{C}, 65 \pm 5 \% \mathrm{RH}$ and $40 \pm 2^{\circ} \mathrm{C}, 75 \pm$ $5 \% \mathrm{RH}$, values of all parameters like percentage of drug content and encapsulation efficiency were evaluated and found to be almost similar to the initial values. The drug dissolution profile was similar to the initial profile. There was no significant change in any value and also no changes in the physical appearance. So it could be concluded that Glibenclamide microparticles prepared with Eudragit RLPO is stable.

\section{CONCLUSION}

Eudragit RLPO microparticles containing Glibenclamide was prepared successfully by using an emulsion solvent evaporation method. By varying the drug: polymer ratios, is found to influence the size, entrapment efficiency and release characteristics of the microparticles. The assessment of the release kinetics revealed that drug release from microparticles was found to be non-Fickian type. Controlled release without initial peak level achieved with these formulations may reduce frequency and improves patient compliance.

\section{ACKNOWLEDGEMENT}

The authors are thankful to Shri C. Srinivasa Baba, Shri G. Brahmaiah and Shri M.M. Kondaiah Management of Gokula Krishna College of Pharmacy, Sullurpet, SPSR Nellore Dist, A.P, India for availing the laboratory facilities during the course of research studies.

\section{REFERENCES}

Behera. BC, Sahoo. SK, Dhal. S, Barik. BB, Gupta. BK., Characterization of Glipizide-Loaded Polymethacrylate Microspheres Prepared By An Emulsion Solvent Evaporation Method. Tropical Journal of Pharmaceutical Research, March 2008; 7 (1): 879-885. [DOI]

Chalk J.B., Patterson M., Smith M.T., Eadie M.J. Correlations between in vitro dissolution, in vivo bioavailability and hypoglycemic effect of oral Glibenclamide. European Journal of Clinical Pharmacology.1986; 31:177-82. [DOI]

Chowdary. KPR, Srinivasa Rao.Y. Design and in vitro and in vivo evaluation of mucoadhesive microcapsules of glipizide for oral controlled release: A technical note. AAPS PharmaSciTech 2003, September 4(3): 87-92. [DOI]

Coppack. SW, AF.Lant, CS.Mcintosh \& AV.Rodgers, Pharmacokinetic and Pharmacodynamic studies of Glibenclamide in non-insulin diabetes mellitus, Br. J. Clin. Pharmac. 1990; 29, 673-684. [DOI]

Dashora, K.; Saraf, S.; Saraf, S., Effect of processing variables and invitro study of microparticulate system of nimesulide. Rev. Bras. Cienc. Farm. vol.43 no.4São Paulo Oct./Dec. 2007. [DOI]

Gohel MC, Amin AF. Formulation and optimization of controlled release diclofenac sodium microspheres using factorial design. J Control Release, 1998; 51: 115-122. [DOI]

Hazedar S, Dortunc B. Preparation and in vitro evaluation of Eudragit ${ }^{\circledR}$ microspheres containing acetazolamide. International journal of pharmaceutics 2004; 269: 131-140. [DOI]

Kumar R, Gupta R.B, Betageri G.V. Formulation, characterization, and in vitro release of glyburide from proliposomal beads. Drug Delivery. 2001; 8:25-27. [DOI]

Langer O., Oral Antidiabetic drugs in pregnancy: the other alternative. Diabetes Spectrum, 2007; 20 (2): 101-105. [DOI]

Lin WJ and Wu TL. Modification of the initial release of a highly water soluble drug from ethyl cellulose microspheres prepared by emulsion solvent evaporation method. Journal of Microencapsulation. (1999) 16: 639-646. [DOI]

Parul Trivedi, AML Verma, N Garud. Preparation and characterization of Aceclofenac Microsphere. Asian Journal of Pharmaceutics. April 2008: 2(2); 110-115. [DOI]

Sahoo SK, Mallick AA, Barik BB, Senapati PC. Formulation and in vitro Evaluation of Eudragit ${ }^{\circledR}$ Microspheres of Stavudine. Tropical Journal of Pharmaceutical Research 2005; 4: 369-375. [DOI]

Salomon C J, Bravo S A, Lamas M A. In-vitro Studies of Diclofenac Sodium Controlled-release from Biopolymeric Hydrophilic Matrices. Journal of Pharmacy and Pharmaceutical Sciences. 2002; 5(3): 213-218. PMid: 12553888

Tripathi KD., Essentials of Medicinal Pharmacology $6^{\text {th }}$ Edition Jaypee publications, 2008; 254-274. [DOI] 